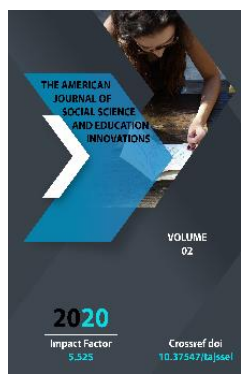

\title{
Teaching The Subject "Mechanics Of Integrated Environments" Based On New Pedagogical Technologies
}

\author{
Zamira Farmonovna Beknazarova \\ Senior Lecturer, Department Of Physics And Chemistry, Tashkent Institute Of Irrigation And \\ Agricultural Mechanization Engineers, Uzbekistan
}

Copyright: Original

content from this work

may be used under the

terms of the creative

commons attributes

4.0 licence.

\section{ABSTRACT}

This article highlights the importance of modern pedagogical technologies, the teaching of physics, and the mechanics of teaching the subject "Mechanics of Unified Environment" based on pedagogical technologies. The theme of the training also included reproductive, productive teaching, working in small groups, and identifying knowledge and skills based on test technologies.

\section{KEYWORDS}

Pedagogical technology, productivity and reproduction teaching, teamwork, testing, elements of fluid and case mechanics.

\section{INTRODUCTION}

There is so much scientific information in each subject that it is impossible to convey to students during the hours they are assigned to traditional teaching methods. Therefore, in the era of high technical development and market economy, an expert needs to gain additional knowledge on his own to be competitive.
Contrary to a thorough development of the methodology of a teacher's classroom curriculum, teaching technology is focused on students' work, creating the necessary conditions for students to master the learning material independently of their personal and collaborative activities with the teacher. 
The central challenge of the educational technology is to ensure that the learning objective is achieved through the development of the student's personality.

\section{MATERIAL AND METHODS}

Although the theory of pedagogical technology has been based since the second half of the last century, there are different approaches to the concept of "pedagogical technology." In particular, pedagogue scientist Bespalko describes pedagogical technology as "a project of a specific pedagogical system that is put into practice" and focuses on the design of the educational and pedagogical process.

It is also important to evaluate the effectiveness of the use of pedagogical technologies in the learning process. The effectiveness of the implementation of pedagogical technologies can be determined by a number of criteria. These are:

- Be able to integrate education, training and personal development tasks;

- Be able to express modern science and technology;

- Ideologically fit the age and psychological characteristics of the students;

- Complete provision of the training material with necessary information;

- The ability to use a variety of techniques and tools in the learning process;

- The principle of transparency and openness of education;

- Ability to use and operate multifunctional learning tools;

- The extent to which the teacher facilitates students to organize independent work.

It is especially important for engineering and construction companies, construction of buildings and structures, and urban and construction specialists to supply gas and drinking water to consumers. In the construction of gas and potable water supply and construction networks, the continuity equation and the Bernoulli equation are important. However, this topic is large and requires a lot of mastering, while less time for teaching. To do this, it is necessary to teach students to work independently at all levels of education, to think creatively and critically, to build their inner motivation and logical thinking skills. These issues are one of the key elements of modern pedagogical technology.

Methods of productive teaching are aimed at developing an individual's ability to learn independently, logical and creative thinking, to quickly understand the cause of the event, to link theoretical knowledge and scientifically grounded knowledge.

The foregoing does not conclude that the method of reproductive teaching is ineffective and not appropriate. In fact, any learning and learning process begins with a reproductive approach. Learning the basics of each subject and having the knowledge resources are reproductive. Only when you have the basic knowledge and skills will you be able to think creatively and solve unknown questions.

The method of working in small groups is a creative work in a classroom where students can study the learning material or perform a task by dividing them into smaller groups to enable learners.

When this method is used, the learner will have the opportunity to work in small groups, be active in the classroom, be in the lead role, learn from each other, and appreciate different perspectives. 
When working in small groups, it can save you more time than other interactive teaching methods. Because the educator is able to simultaneously engage and evaluate all students.

The steps of the method of working in small groups are:

1. The direction of activity is defined. Related issues are identified on the topic.

2. Subgroups are marked. Students can be divided into groups of 2-5 people.

3. Small groups begin to complete the task.

4. Clear instructions are given and directed by the educator.

5. Small groups make presentations.

6. Completed tasks are discussed and analyzed.

7. Small groups are evaluated.

Modern pedagogical technology places great emphasis on teaching students critical thinking, mental attack and teamwork. The aim of the scientific work is to study "Elements of mechanics of fluid and gases" in group method of modern pedagogic technology. In the classroom, students are grouped into small groups ( 2 to 5 people) to use. These groups can then be entrusted with mastering the same content.

The following should be considered when designing the materials and tests to be distributed to groups.

The fluidity of the fluids under external pressure is the property of fluidity. The gases are compact, absorbable and readily absorbed. The similarity of gas and fluid sizes should be taken into account when applying the same approach to their study.
Laws of Pascal, Archimedes, Puazeyli, Newton for fluids and gases. Continuity equation $(\vartheta \rho$ $/ 2)^{2}+\rho g h+p=$ const - Bernoulli equation. Their use in life and technique. Hydrostatic, dynamic, static pressures, and rotation of axes.

Hydromechanics, aeromechanics - a part of mechanics.

Fluid viscosity (viscosity) and its dependence on temperature and velocity. Laminar and turbulent flow. Reynolds number. The behavior of objects in liquids and gases.

The benefits of group work help the student to develop a culture of questioning and the ability to think critically, independently, and collaborate. Through teamwork, it is possible to achieve high level of thinking, deep learning, building positive and friendly relationships among members of the group, and spiritual harmony between them. Students teach each other. There are opportunities for effective use and self-management during the lessons. The purpose and content of the group setting should be carefully thought out, and the team should be able to provide scientifically sound handouts, technical equipment and facilities. Group formation should take into account student relationships, characteristics, gender, their level of knowledge and activity. The teacher should be fully informed about each student. All groups should be composed of students, taking into account their level of knowledge. Groups should be appointed and provided with handouts, appropriate literature and technical facilities. During group work, students can ask the teacher any questions related to the topic.

The task of the teacher is to organize the groups correctly, clearly and fully describe the purpose of answering the questions, technical 
tools, list of literature, oral, written questions, test preparation, assessment of group activities, as well as the knowledge of each student. to control, not to leave. Replacing group members in each group work also yields good results.

It should be noted that "Elements of fluid and gaseous mechanics" must be mastered during one theoretical course. Therefore, preparation for this lesson must be announced in advance at least one week before the class, and all necessary facilities must be created. The procedure for conducting the lessons after the preparatory phase is as follows: one student from each group is invited to a blackboard. Students can ask the teacher along with the teacher. However, the number of questions should be limited. It is not allowed to ask illogical questions. All students are tested this way. The teacher evaluates each student's answers, questions, and enthusiasm for the lesson. The knowledge of groups working in the same context is compared with tests. The final grade will also be based on current estimates. The performance of the group is evaluated based on the evaluation of the group members. Student knowledge can also be assessed through written work or tests.

\section{CONCLUSIONS}

Effective use of pedagogical technologies in the learning system also depends on the professional competence of the teacher. Therefore, the effectiveness of pedagogical technologies can also be evaluated by the teacher in their use. The following criteria are important:

- Technological culture of the teacher;

- Experience of the teacher in the application of pedagogical technologies;
- "Creative" changes in pedagogical technologies by teachers and their transformation;

- Successful implementation of pedagogical technologies in educational practice based on collaboration between teachers and students;

- Interaction between components of pedagogical technologies;

- Availability of pedagogical technologies for professional development of students and teachers;

- Positive importance of students' educational activities

It is difficult to combine all of the topics in groups, but it is advisable to organize at least a few lessons each semester.

\section{REFERENCES}

1. Farberman B.L., Musina R.G., Jumabayeva F.A. Higher Education modern teaching methods in their home countries. Tashkent 2002.

2. Ganiev F. S., Indiaminov N. N. Descriptive subjects specific subjects teaching on principles. New Pedagogy in Continuing Education and information technology. Samarkand 2003. - pp. 94-96.

3. Pespalko V.P. Components of educational technology. - M.: Pedagogy, 1989.

4. Physics textbooks for higher education institutions

5. Rustamiy, S. (2018). Typological peculiarties of science of balaghah, rhetoric and stylistics. The Light of Islam, 2018(1), 16.

6. Rustamiy, S. A. (2020). Content of components of the science balagat. ACADEMICIA: An International 
Multidisciplinary Research Journal, 10(10), 1332-1337.

7. Axmedovna, J. N., Gapporovna, S. M., Rozmatovna, A. O., \& Tashkent, U.Z. B. E. K. I. S. T. A. N. (2019). THE IMPORTANCE OF NEEDS ANALYSIS IN TEACHING ESP. European Journal of Research and Reflection in Educational Sciences Vol, 7(11).

8. Sodirjonov, M. M. (2020). Some Thoughts On The Evolution Of Approaches To The Concept Of Human Capital. The American Journal of Social Science and Education Innovations, 2(08), 144-150.

9. Beknazarova, Z. F. (2019). INNOVATIVE APPROACH TO TEACHING PHYSICS. Scientific Bulletin of Namangan State University, 1(12), 245-249.

10. Omonovich, K. D., Farmonovna, B. Z., \& Anatolievna, K. M. (2019). GROUP CREATIVITY DEVELOPMENT TECHNOLOGY IN THE EDUCATION SYSTEM. European Journal of Research and Reflection in Educational Sciences Vol, 7(12). 